\title{
Chordoid Glioma of the Third Ventricle, a Rare Tumor with an Unexpected Outcome
}

\section{Glioma cordoide do terceiro ventrículo, um tumor raro com um resultado inesperado}

\author{
Pedro Ribeiro da Cunha ${ }^{1}$ Olinda Rebelo ${ }^{2}$ Marcos Barbosa ${ }^{1}$ \\ ${ }^{1}$ Neurosurgery Service, Centro Hospitalar e Universitário de Coimbra, \\ Portugal \\ ${ }^{2}$ Neurology Service, Neuropathology Laboratory, Centro Hospitalar e \\ Address for correspondence Pedro Ribeiro da Cunha, MD, Centro \\ Hospitalar Universitário de Coimbra, Praceta Prof. Mota Pinto, 3000- \\ Universitário de Coimbra, Portugal
}

Arq Bras Neurocir 2017;36:32-37.

\begin{abstract}
Chordoid glioma is a rare tumor of the third ventricle whose imaging features are difficult to distinguish from other more common lesions in this location. There are only 83 cases described so far in the literature. Although gross total resection (GTR) is the treatment of choice, immediate postoperative mortality with this approach can be as high as $29 \%$, and morbidity among survivors can reach $67 \%$. We report a case of a male patient of advanced age, with a third ventricle mass lesion, who presented with a progressive right temporal hemianopia. Imaging was compatible with craniopharyngioma, meningioma or even metastasis. Chordoid glioma was not considered in the

\section{Keywords}

- chordoid glioma

- third ventricle

- gross total resection

\section{Resumo}

\section{Palavras-chave}

- glioma cordoide

- terceiro ventrículo

- remoção macroscópica total differential diagnosis. The patient underwent surgery and GTR was achieved. There were no postoperative complications, and the patient was discharged from the hospital three weeks later. Unexpectedly, two days afterwards, he suffered a major brainstem hemorrhagic stroke and, unfortunately, died.

O glioma cordoide é um tumor raro do terceiro ventrículo, e as suas características imagiológicas são difíceis de distinguir de outras lesões mais comuns nesta localização. Até a data presente, existem apenas 83 casos de gliomas cordoides descritos na literatura. A remoção macroscópica total destes tumores deve ser o tratamento de escolha; no entanto, a mortalidade pós-operatória imediata pode chegar aos $29 \%$, e a morbilidade pode atingir os $67 \%$ entre os sobreviventes. Nós descrevemos o caso de um homem idoso com uma lesão tumoral no terceiro ventrículo, que se manifestou com uma hemianopsia temporal direita progressiva. Os exames de imagem eram compatíveis com craniofaringioma, meningioma ou até metástase. O glioma cordoide não foi considerado como uma das hipóteses no diagnóstico diferencial inicial. O paciente foi submetido a cirurgia, tendo-se obtido a remoção macroscópica total. Não houve qualquer complicação no período pós-operatório, e o paciente teve alta hospitalar após três semanas. Inesperadamente, dois dias após a alta clínica, o paciente sofreu um AVC hemorrágico do tronco cerebral, e acabou por falecer.
\end{abstract}

received

October 7, 2016

accepted

December 29, 2016
DOI http://dx.doi.org/

10.1055/s-0037-1599062. ISSN 0103-5355.
Copyright $\odot 2017$ by Thieme Revinter Publicações Ltda, Rio de Janeiro, Brazil
License terms

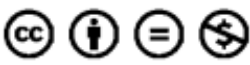




\section{Introduction}

Chordoid glioma is a rare, low-grade tumor (WHO II) of the third ventricle, first described by Brat in $1998 .{ }^{1}$ Its imaging features are difficult to distinguish from other more common lesions in this location. There are only 83 cases described so far in the literature. ${ }^{2-4}$

Due to the location of these tumors, they usually present with symptoms of intracranial hypertension caused by obstructive hydrocephalus, hypothalamic dysfunction and/or visual deficit. ${ }^{2}$ Gross total resection (GTR) is the treatment of choice, since no recurrence has been reported after a macroscopically complete resection; however, this is not always possible because of the location of the tumor and its adherence to the hypothalamus. ${ }^{3}$ Mortality in the immediate postoperative period after surgical resection can be as high as $29 \% .^{1}$ The major causes of death, namely, pulmonary embolism, myocardial infarction and infection, ${ }^{2}$ are not directly related to the surgical procedure.

To the best of our current knowledge, our case is the first report of a spontaneous brainstem hemorrhage as cause of death after surgical excision of a chordoid glioma.

\section{Case Report}

Presentation: The patient is a 71-year-old man with history of an accidental trauma to the left eye, which resulted in complete blindness, and also a previous right eye catarac, that presented with an 8-month progressive visual loss in the right eye. He was referred to neurosurgery by his ophthalmologist, who did not believe the visual impairment was related to the cataract.

He had no other complaints, no relevant past medical history, or use of chronic medication. Apart from the right temporal hemianopia, the neurological examination was unremarkable. Physical stigmas of pituitary dysfunction were also excluded.

The computerized static perimetry (CSP) exam confirmed right temporal hemianopia and - left-eye amaurosis (sequelae of a previous accident)

A head magnetic resonance imaging (MRI) revealed an extra-axial, suprasellar, mass lesion, isointense on T1-weighted images, hyperintense on T2, and with heterogeneous strong enhancing after gadolinium contrast administration, except for a small cystic focus located in the inferior margin. Its dimensions were $5 \mathrm{~cm}$ in vertical diameter, 2.7 antero-posterior, and 1.7 in lateral. It was localized over the pituitary stalk, but with no correlation to the pituitary gland, displacing the optic nerves laterally, and compressing the chiasm. The first diagnostic hypothesis was of a craniopharyngioma (-Fig. 1A-C).

Treatment: The patient was submitted to surgery, and gross total resection was apparently achieved using a transSylvian and a trans-lamina terminalis approach. The pituitary stalk had to be sacrificed.

Histological examination revealed a chordoid glioma of the third ventricle with positive immunohistochemistry for vimentin, glial fibrillary acidic protein (GFAP), cell antigen
CD 34 and negative for cytokeratin MNF 116 and S100. The index of monoclonal antibody $\mathrm{K}_{\mathrm{i}}-67$ was lower than 1\% (-Fig. 2).

Postoperative course: The postoperative computerized tomography (CT) scan showed apparent GTR, and no associated complications (-Fig. 3). Although we are aware that complete excision of the lesion can only be confirmed by MRI, our department's strategy with brain tumors is to perform this imaging exam at 2 months post surgery. The patient had no immediate postoperative additional morbidity, and was discharged from the hospital after three weeks. Two days later, he had an unexpected hypertensive crisis that resulted in extensive brainstem hemorrhage and subdural hematoma. Unfortunately, the patient did not survive. (-Fig. 4)

\section{Discussion}

Chordoid Glioma is a rare low-grade tumor that is always found in the third ventricle. It is unique in its topography, female gender predominance, stereotypical histology and radiological features. Because of the singular features of chordoid gliomas, these tumors are difficult to group with other neoplasms, and this is why they are included in the other gliomas section of the recently published 2016 WHO classification of brain tumors. $^{5}$

To date, 83 cases of chordoid glioma have been reported in the literature. ${ }^{2-4}$

Chordoid gliomas occur in adult patients with a mean age of 46 years, and with a 2:1 female predominance. There are only 3 reports of a chordoid glioma in children: a 12-year-old boy ${ }^{6}$ and two girls, one aged 7, and the other $13.7,8$

The presenting symptoms reported are headache and vomiting, visual disturbances, gait difficulties, fatigue, syncopal episodes, urinary incontinence, weight gain, hyperphagia, hypothyroidism, memory loss and psychosis. ${ }^{9}$ These symptoms are not specific, and are related to the coexisting hydrocephalus, or are due to the invasion in or mass effect on surrounding structures such as the hypothalamus, optic the chiasm or the fornices. Calanchini et $\mathrm{al}^{3}$ described a unique form of presentation, so far consisting of a chordoid glioma presenting with hyponatremia due to the inappropriate secretion of the antidiuretic hormone (ADH). Most patients present with several months or even years of clinical history..$^{9}$ There is only one report by Gallina et al of an incidentally diagnosed chordoid glioma after a minor head injury. $^{10}$

Our case has some rare features. It is a case of a male patient, older (71 years old) than the usually described patients, with a previous eye pathology, in which the diagnosis of the chordoid glioma was most likely precipitated by the accidental ocular trauma that resulted in left eye blindness. In our interpretation, the patient probably already had some visual deficit for several months, or even years, but did not complain about it. Only after the accident, being blind in the left eye, he noticed he was also losing vision of his only useful eye (right). The difficulty in this case, besides the advanced age of the patient, was also the lack of other 
34 Chordoid Glioma of the Third Ventricle, a Rare Tumor with an Unexpected Outcome Cunha et al.
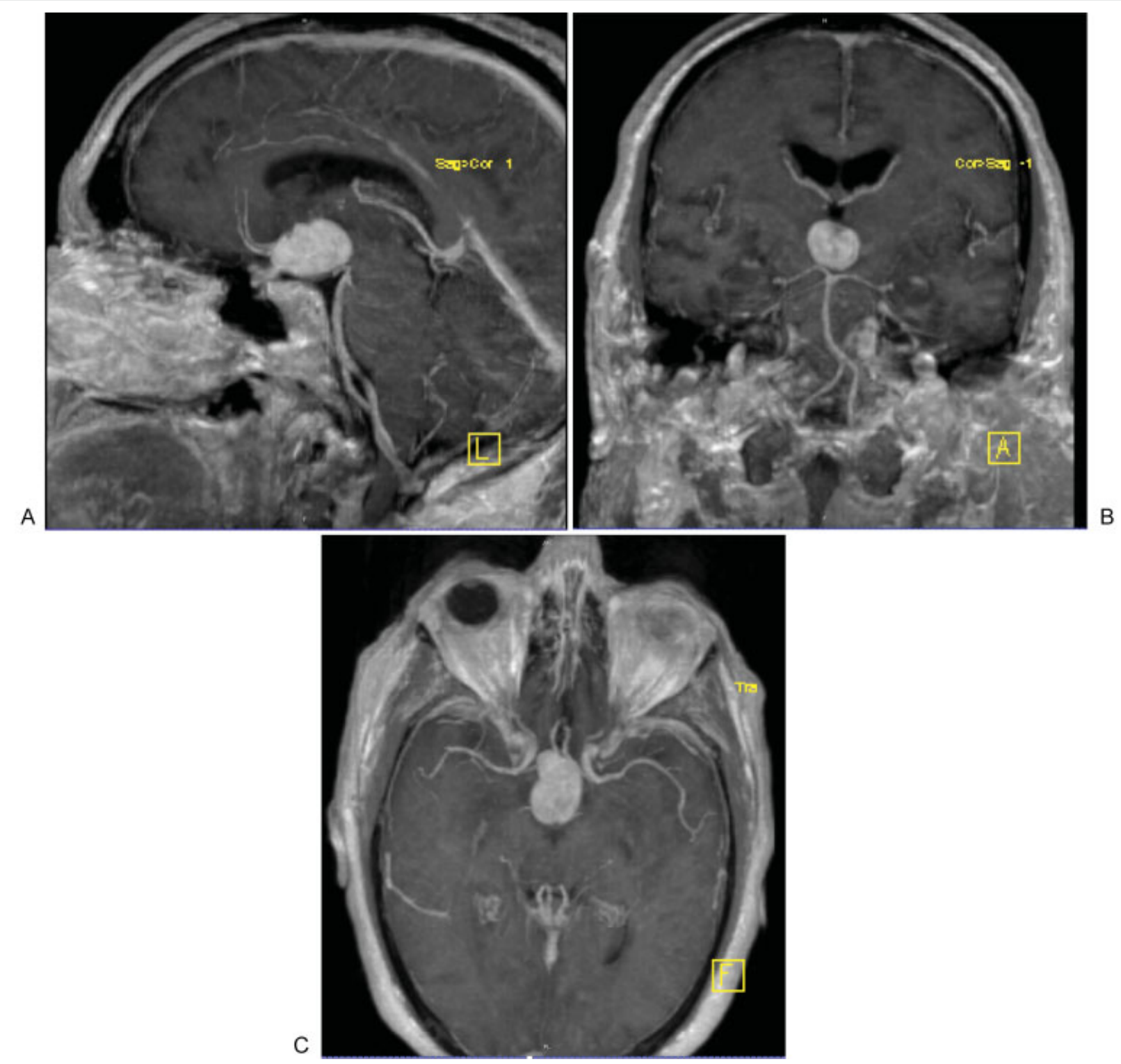

Fig. 1 Gadolinium-enhanced T1 weighted MRI images, sagittal (A), axial (B) and coronal (C), depicting an extra-axial, suprasellar mass lesion, with strong heterogeneous enhancement, except for a small cystic focus located in the inferior margin. The lesion is $5 \times 2.7 \times 1.7 \mathrm{~cm}$ in vertical, the antero-posterior and transverse axis respectively. It is laterally displacing the optic nerves and compressing the optic chiasm.

symptoms. The outcome after discharge from the hospital three weeks after the operation was also totally unexpected.

According to Pomper ${ }^{11}$, chordoid gliomas are ovoid in shape, well circumscribed, located in the anterior third ventricle, and separated from the pituitary gland. They are isointense on T1-weighted images, and are uniformly enhanced after gadolinium contrast administration. Most tumors are solid, but in $25 \%$ of them, a small central cystic area is present. The differential diagnosis includes other third ventricular lesions, such as craniopharyngioma, ependymoma, central neurocytoma, pituitary macroadenoma, choroid plexus papilloma and meningioma. In our case, due to the advanced age of the patient and the cystic aspect of the lesion in the MRI, the first diagnostic hypothesis was a craniopharyngioma. Additionally, our case is included in the rarer $25 \%$ of chordoid gliomas that present with a central cystic area.

Similar to the majority of the reports in the literature, in our case, the histopathological exam revealed a chordoid glioma immunohistochemically stained for GFAP, vimentin, CD 34 and epithelial membrane antigen (EMA), and negative reactivity for MNF 116 and S100, with $\mathrm{K}_{\mathrm{i}}-67$ lower than $1 \%$. Lastly, we also observed positive immunoreactivity for D240 and negative for neurofilament protein (NFP). Monoclonal antibody D2-40 is known to act against M2A protein derived from germ cell tumors, which makes it a useful marker for ependymal tumors, especially when combined with EMA. ${ }^{12}$

This way, in our case, adding the positive immunoreactivity for D2-40, for EMA and GFAP and the negativity for NFP points to a more likely ependymal origin of chordoid gliomas, 


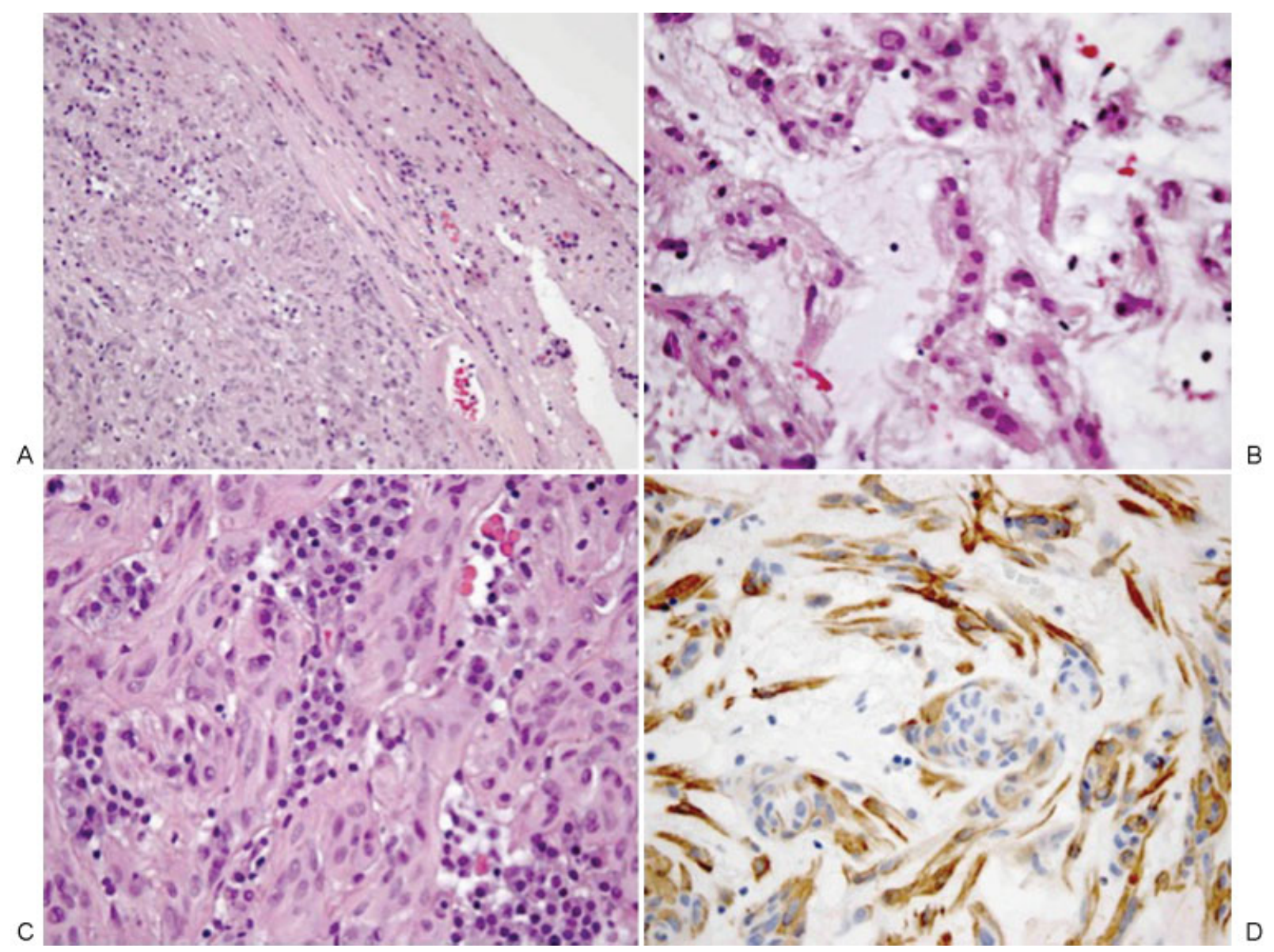

Fig. 2 (A) - Hematoxylin-Eosin (HE), 200x, ventricular tumor lined up by a fibrous capsule; (B) - HE, 400x, tumor cell cords surrounded by myxoid stroma; (C) - HE, 400x, solid tumor areas with lobule formation, abundant lymphocytes and Russell bodies; (D) -HE, 400x positive immunoreactivity for glial fibrillary acidic protein (GFAP) in chordoid glioma tumor cells.

as described in the majority of the previous reported cases in the literature.

Gross total resection is the treatment of choice for chordoid gliomas, since no recurrence has been reported after a macroscopically complete resection, but this is often difficult because of the size and location of the tumor and its adherence to the hypothalamus. ${ }^{3}$ When this is the case, the risk of surgical morbidity cannot be ignored.

Other authors have suggested that a less invasive surgical treatment, with or without the addition of gamma knife radiosurgery, can provide a safer and more effective therapeutic approach to these lesions. ${ }^{13}$

However, previous reports show that, when not completely resected, chordoid gliomas can continue to grow slowly, and some patients have a poor outcome; ${ }^{14,15}$ so, whenever possible, in our perspective, GTR should be the goal.

Additionally, in a recent review by Ampie et $\mathrm{al}^{2}$ that gathered 81 cases of surgically treated chordoid gliomas, there were 31 patients (37\%) suffering from postoperative complications, and 18 (22.2\%) deaths, none related to tumor progression. Although reported morbidity and mortality were considerably high, there was no association with the extent of resection, age or tumor size. Moreover, patients in

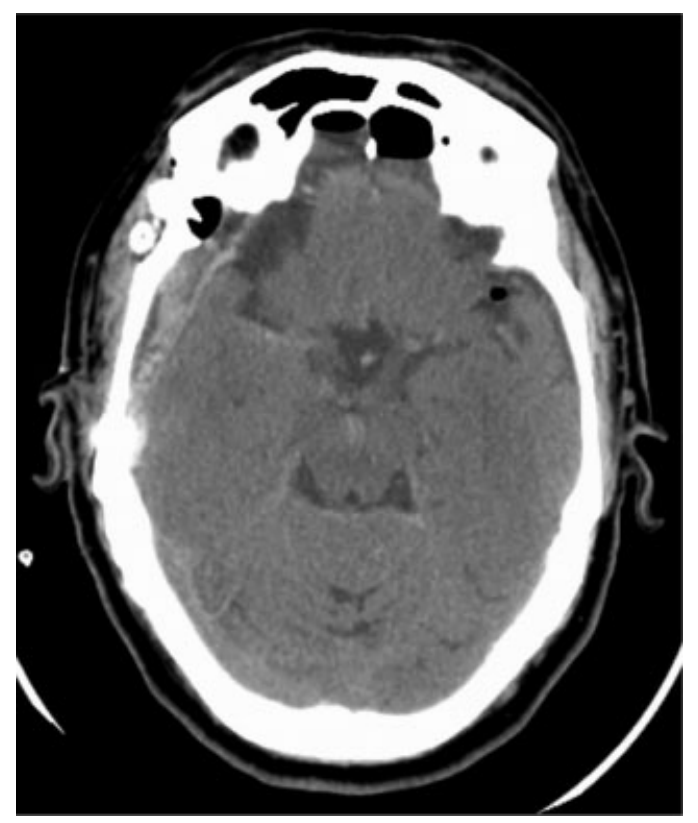

Fig. 3 Axial non-contrast enhanced CT scan showing apparent gross total resection of the third ventricle tumor lesion, with no associated complications. 


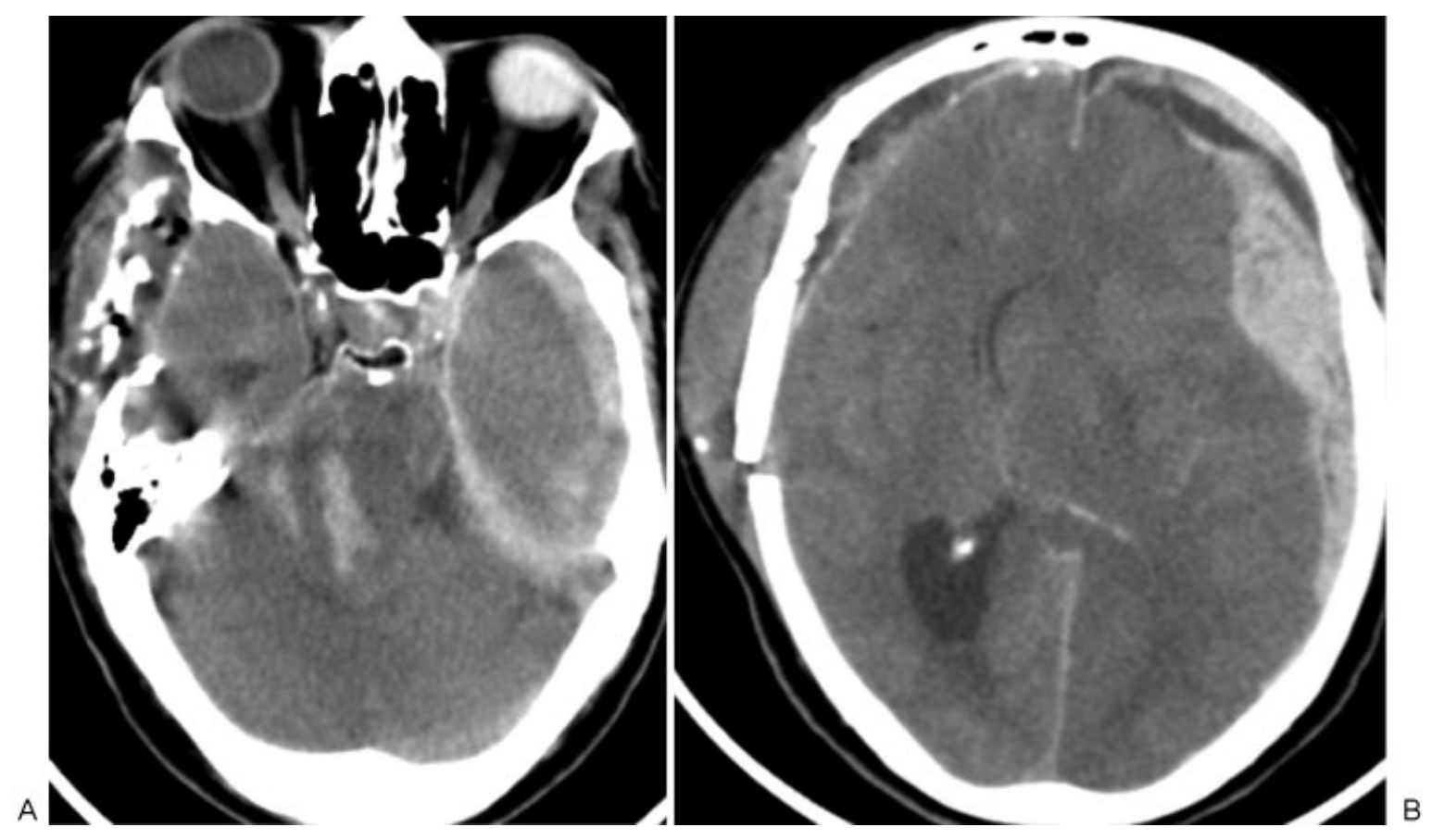

Fig. 4 Axial non-contrast enhanced CT scan three weeks after surgery revealing an extensive brainstem hemorrhage (A) and a left massive subdural hematoma associated with mass effect and subfalcine herniation (B) that resulted in the patient's death.

whom GTR was achieved had no tumor progression, while a progression of $25 \%$ and $14.7 \%$ was noted after biopsy and subtotal tumor resection (STR) respectively.

In the same review, when comparing the transcortical and transcallosal approaches with the trans-lamina terminalis approach, this last one showed a strong trend towards decreased overall rates of postoperative morbidity, although this difference did not achieve statistical significance $(p=0.051)$.

In our case, GTR through a transSylvian trans-lamina terminalis approach was possible. The patient was discharged from the hospital three weeks later, with no major postoperative complications. He was started on hormonal therapeutic substitution due to hypopituitarism, a consequence of pituitary stalk section during surgery, but besides that, the patient had no additional morbidity. However, 48 hours later he had a major brainstem hemorrhagic stroke associated with a subdural hematoma, following a hypertensive crisis, and unfortunately died. There was no trauma related to the event. This was totally unexpected and, to the best of our knowledge, it is the first case described in the literature of a hemorrhagic stroke as a cause of death after surgical resection of a chordoid glioma.

Previous reports on death causes after chordoid glioma surgery reach as high as 18 cases $(22.2 \%)$ out of 81 patients, and 50\% (9 patients) of them died in the first 18 days after surgery. ${ }^{2}$ Most patients died from pulmonary embolism, infectious causes or myocardial infarction. No death related to the disease's progression was reported.

There are three reports of postoperative hematoma after chordoid glioma surgery, ${ }^{7,13,16}$ and none resulted in the patient's death. In one report, the patient had an intraven- tricular bleeding that was surgically evacuated, but the patient died one week later, from another cause, namely bacterial meningitis. ${ }^{7}$ In another case, there was a small subfrontal hematoma, but with no further consequence for the patient. ${ }^{13}$ Another report of a postoperative subdural hematoma and hemorrhage in the surgical field was managed conservatively, and the patient recovered after one week. ${ }^{16}$

We can only speculate about what caused this major brainstem hemorrhage and subdural hematoma that eventually resulted in our patient's death. There was no associated head trauma, the patient was lying in his bed when a neurological deterioration was noted. The patient had no previous history of hypertension before surgery, so maybe the hypertensive crisis was a consequence of the iatrogenic hormonal imbalance that followed the GTR of the tumor accompanied by the section of the pituitary stalk. Although hormonal substitution treatment was started, this must have interfered with the arterial blood pressure regulation mechanisms and, associated with the advanced age of the patient and vascular fragility, ended up causing a major hemorrhagic stroke and subdural hematoma.

\section{Conclusions}

The third ventricle chordoid glioma is an uncommon tumor with an uncertain origin; however, it must be considered in the differential diagnosis of third ventricle tumor lesions, even in older male patients.

Although surgical resection, especially GTR, is considered the gold standard, the high morbidity and mortality associated with the procedure cannot be ignored. For older and 
other high-risk patients, planned subtotal resection followed by stereotactic radiosurgery may be a safe, effective alternative, and should be taken into account. For this issue, further studies, with longer follow-up periods are needed to understand the role of radiotherapy and radiosurgery in the management of these tumors.

Furthermore, even though the immediate postoperative course might be uneventful, major complications resulting in patient death seem to occur after the second postoperative week. Therefore, close surveillance of these patients is advised in the first weeks after surgery, especially regarding hormonal substitution and thromboembolic event prophylaxis.

\section{Disclosure}

The authors declare that they have no conflicts of interest. The family of the patient has consented to the submission of the case report to the journal.

\section{References}

1 Brat DJ, Scheithauer BW, Cortez SC, et al. Chordoid glioma of the third ventricle. IN: Kleihues P, Cavenee WK, eds. Pathology and genetics: Tumours of the Nervous System. World Health Organization Classification. Lyon: International Agency for research on Cancer Press; 2000:90-91

2 Ampie L, Choy W, Lamano JB, et al. Prognostic factors for recurrence and complications in the surgical management of primary chordoid gliomas: A systematic review of literature. Clin Neurol Neurosurg 2015;138:129-136

3 Calanchini M, Cudlip S, Hofer M, Byrne J, Fabbri A, Grossman A. Chordoid glioma of the third ventricle: a patient presenting with SIADH and a review of this rare tumor. Pituitary 2016;19(04): 356-361
4 Poyuran R, Mahadevan A, Sagar BK, Saini J, Srinivas D. Chordoid Glioma of Third Ventricle With an Epidermoid Cyst: Coexistence or Common Histogenesis? Int J Surg Pathol 2016;24(07):663-667

5 Louis DN, Perry A, Reifenberger G, et al. The 2016 World Health Organization Classification of Tumors of the Central Nervous System: a summary. Acta Neuropathol 2016;131(06):803-820

6 Castellano-Sanchez AA, Schemankewitz E, Mazewski C, Brat DJ. Pediatric chordoid glioma with chondroid metaplasia. Pediatr Dev Pathol 2001;4(06):564-567

7 Jain D, Sharma MC, Sarkar C, et al. Chordoid glioma: report of two rare examples with unusual features. Acta Neurochir (Wien) 2008;150(03):295-300, discussion 300

8 Morais BA, Menendez DF, Medeiros RS, Teixeira MJ, Lepski GA. Chordoid glioma: Case report and review of the literature. Int J Surg Case Rep 2015;7C:168-171

9 Pasquier B, Péoc'h M, Morrison AL, et al. Chordoid glioma of the third ventricle: a report of two new cases, with further evidence supporting an ependymal differentiation, and review of the literature. Am J Surg Pathol 2002;26(10):1330-1342

10 Gallina P, Pansini G, Mouchaty H, Mura R, Buccoliero AM, Di Lorenzo N. An incidentally detected third ventricle chordoid glioma. Neurol India 2007;55(04):406-407

11 Pomper MG, Passe TJ, Burger PC, Scheithauer BW, Brat DJ. Chordoid glioma: a neoplasm unique to the hypothalamus and anterior third ventricle. AJNR Am J Neuroradiol 2001;22(03):464-469

12 Ni HC, Piao YS, Lu DH, Fu YJ, Ma XL, Zhang XJ. Chordoid glioma of the third ventricle: four cases including one case with papillary features. Neuropathology 2013;33(02):134-139

13 Kobayashi T, Tsugawa T, Hashizume C, et al. Therapeutic approach to chordoid glioma of the third ventricle. Neurol Med Chir (Tokyo) 2013;53(04):249-255

14 Kurian KM, Summers DM, Statham PFX, Smith C, Bell JE, Ironside JW. Third ventricular chordoid glioma: clinicopathological study of two cases with evidence for a poor clinical outcome despite low grade histological features. Neuropathol Appl Neurobiol 2005; 31(04):354-361

15 Jung TY, Jung S. Third ventricular chordoid glioma with unusual aggressive behavior. Neurol Med Chir (Tokyo) 2006;46(12): 605-608

16 Liu WP, Cheng JX, Yi XC, et al. Chordoid glioma: a case report and literature review. Neurologist 2011;17(01):52-56 